\title{
LOS PABLOS
}

Néstor Pichardo*

El sonido del viento rasgando las calles de Jericó traía consigo el llanto agudo de un bebé. El aire, caliente e inmisericorde, arrastraba hacia el kiosco el polvo rojizo que cubría todas las calles. Casi terminaba su recorrido por todas las casas de adobe que conformaban el minúsculo pueblo, llevando consigo la noticia del nacimiento de Pablo.

Resultaba casi increíble que en aquel lugar, último refugio de la época revolucionaria, pudiera nacer de nuevo un niño. Para ser exactos habían pasado ya veintinueve años desde que una mujer diera a luz en aquel paraje desolado. Se decía que el lugar era tan infértil que no solo su tierra sino las mujeres por igual habían caído víctimas de aquella antigua maldición.

Atrapado en una constante pobreza, Jericó fue uno de esos pueblos que ni antes ni después habían tenido una etapa de gloria. Siempre al margen, su población no llegaba a las seiscientos almas, en su mayoría ancianos que velaban por la salvedad de un lugar que no tenía ya salvación.

Callejuelas rústicas, encrucijada de pasajes que se abrían alrededor del kiosco, hechas de piedra y terracería que ni el más ducho conductor

* Néstor Pichardo (Ciudad de México, 1992) es comunicólogo y escritor, ganador del Premio Nacional de Novela Joven José Revueltas 2018 y autor de De las cenizas en la tierra (FETA, 2018). Es secretario de Redacción y colaborador de El Universal. 
podía recorrer en su automóvil. Calles semi desiertas donde el llanto que, después se supo, era de dos infantes, resonó ante la mirada incrédula de los ancianos sentados en los portales de sus desvencijados hogares.

Como en todos los pueblos minúsculos, la mayoría de los habitantes resultaban ser parientes del recién nacido, por lo que acudieron, en los días posteriores, a visitar al menor. Muchos, más que por cariño, se acercaban a la humilde vivienda por curiosidad. Empujaban un poco la puerta de madera carcomida que en algún tiempo fue azul, entraban pidiendo permiso, saludando al primo que hace meses no se veía, esquivando la hamaca se enfilaban hacia la cama y observaban atentos al que se convertiría algún día en el miembro más notable de su comunidad.

La razón de la gran popularidad que invadía el hogar de los Romero era que el recién traído al mundo valía por dos. De los pies al cuello todo parecía encontrarse en armonía con los demás habitantes del pueblo, pero al llegar a su cabeza nadie podía evitar la gran sorpresa que les producía encontrar a dos niños diferentes.

"Los Pablos" como se les nombró en el pueblo, eran un solo ser humano con dos cabezas. No me refiero a un cráneo funcional y a una tumoración inerte a su lado, como los doctores dictaminaron en un principio; en verdad eran dos personas que compartían el mismo cuerpo como se fue confirmando con el crecimiento del menor (de los menores, podríamos aclarar).

Con el paso del tiempo se observó que no existía mayor dificultad en el desarrollo de los niños. Jugaban con el mismo cuerpo, corrían libremente y aprendieron a hablar a la par, entablando sus primeras conversaciones entre ellos mismos, los únicos infantes de Jericó. Nunca se tuvo claro quién movía qué parte de su fisionomía pero lo hacían con una soltura casi increíble que los llevó a destacar en diversos deportes a la edad de ocho años.

Sus padres, ya viejos y mancillados por la vida del campo, cuidaron de sus hijos con lo que sus posibilidades les permitían. Se decía por el pueblo que alguna bruja había maldecido a la señora Teresa de Romero por alguna infamia cometida en su contra. Otros, como el Padre Ramón, 
señalaban el hecho como una bendición del señor que mandó a dos de sus ángeles para compartir un cuerpecito.

La historia de los dos niños en un cuerpo cundió velozmente por los pueblos y rancherías colindantes. Para cuando los jovencitos tuvieron la oportunidad de asistir a la escuela, su fama les precedía.

Así fue entonces que, rodeados de la expectativa popular, los Pablos comenzaron a resaltar también en el ámbito escolar, de formas diferentes. El Pablo derecho (para precisar) comenzó a crear problemas en el colegio mientras que el Pablo izquierdo logró destacar enormemente en rendimiento académico.

Incapaces de reprobar a uno y premiar al otro, a las autoridades les parecía injusto frenar el promisorio avance de Pablo izquierdo. Después de una larga plática entre profesores, se decidió apoyar a los Pablos juntos, a pesar de las barbaridades que cometía el hermano del lado derecho.

Los grandes esfuerzos de Pablo izquierdo lo llevaron a conseguir financiamiento para sus estudios, becas, apoyos diversos que se vieron reflejados algunos años después en la remodelación de la casa y de la parcela de los Romero. Contrastante con su entorno, se alzaba ya una casa de dos pisos, mitad azul y mitad roja, donde los padres de los Pablos pasaron sus últimos años.

Pablo derecho, escudado en la erudición y buen comportamiento de su hermano, escupía, gritaba, molestaba y se burlaba mientras el pobre izquierdo lo instaba educadamente a guardar silencio. Muchas veces los castigos eran para ambos y las nalgadas las lloraban por igual.

Así se formaron las dos personalidades de los Pablos. Con el tiempo todos adoraban al izquierdo e intentaban permanecer lo más alejados del derecho, lo cual resultaba imposible pues los vituperios resonaban fuertes y claros. Avergonzado, uno de los hermanos, con el color rojo encendido en su piel color leche, fingía no escuchar y ofrecía disculpas al tercero en cuestión.

Su fama para ese entonces ya se había extendido a lo largo del país. Entre entrevistas y conferencias se fueron yendo los años donde Pablo derecho, con una seguridad innata, se mostraba a sí mismo como el 
responsable de la gran notoriedad y carisma de los hermanos. Pablo izquierdo, con un semblante nervioso, se limitaba a asentir todo lo que su mentiroso hermano aseguraba.

La popularidad los hizo salir de Jericó, después de la muerte de sus padres. Izquierdo se despidió con gran sentimiento de las calles polvosas, de la parcela de sus padres, del riachuelo que pasaba debajo del puente Porvenir. Derecho se limitó a mentar algunas madres a personas que lo despreciaban sobremanera y, caminando por la única avenida asfaltada del pueblo, salieron con la idea de nunca más volver.

Los ancianos del pueblo observaron pasivamente cómo la figura del muchacho con dos cabezas, una derramando lágrimas y la otra con ceño impenetrable, se alejaba. El único rastro de su nacimiento en Jericó fue un museo en su honor que se erigió dentro de la casa que le habían construido a sus padres.

Encontrar un lugar en la capital no les fue en absoluto difícil. Ante personas que alaban la extrañeza y, sobretodo, la demagogia, el camino estaba allanado por la facilidad de palabra de Pablo izquierdo. Derecho, cabe mencionar aquí, también se vio seducido por las facilidades que el dinero trae consigo. Cedieron prontamente al falso perfume de importancia y poder que de la moneda emana.

Ya con una vida citadina y sumamente ocupada (eran los presentadores de un talk show de horario estelar) poco a poco olvidaron la sencillez del pueblo que los vio nacer. Engreídos ya los dos, sus excesos comenzaron a ser blanco de amarillismo y atención desmedida. Izquierdo comenzó a beber en demasía y Derecho se había hecho famoso por ser un buscapleitos de la vida nocturna.

Las mujeres que los rodeaban en aquellos años de excesos aseguran que la personalidad tímida de Izquierdo era superada con el alcohol. Víctima de una copa tras otra, se transformaba en un ser capaz de sostener sus argumentos y no ceder ante los chantajes de su hermano, lo cual devenía, en muchas ocasiones, en gigantescos escándalos.

Aunado a la lenta corrosión que la fama y el dinero causaban en ellos, una variable peculiar entró en juego para los hermanos del momento, el día en que celebraban su cumpleaños veintinueve. En algún olvidado 
pueblecillo, cuyo nombre parecían recordar, un recién nacido había tenido la maldición (o la fortuna) de haber nacido con tres cabezas independientes entre sí que compartían el mismo cuerpo.

Sintieron la amenaza de ya no sentirse únicos en este mundo y decidieron tomar cartas en el asunto. Los contactos hechos a lo largo de su estancia en la capital les brindaron las facilidades para opacar aquel molesto suceso, como le llamaban. Los espacios televisivos dejaron de dedicar tiempo a los Ramones, como se les comenzaba a conocer, y agentes especiales custodiaban que ningún reportero o cazatalentos se acercara a Jericó.

En una de aquellas noches vertiginosas, irritados por la situación, podría pensarse, los hermanos discutieron, según su costumbre. A quién se debía la gran popularidad que los había llevado tan lejos, quién de los dos era el alma verdadera de los Pablos. El tono del pleito aumentó después de que salieron del bar, durante el trayecto a casa (así lo afirma su chofer), e incluso en el elevador que subía al penthouse de la avenida Reforma.

El vigilante del imponente edificio confiesa haber escuchado un tremendo alboroto en el piso de los Pablos pero, al ser esto usual, no se alarmó demasiado. Tal vez este modesto hombre hubiese sido el único que, de haber sido testigo, informara sobre la verdad de aquella noche.

Al día siguiente el show de Los Pablos y amigos se canceló. No hubo entrevistas ni noticias de los hermanos durante semanas posteriores. La policía comenzó a investigar la extraña desaparición de las celebridades del momento, buscando por todas las ciudades importantes, no solo del país, sino de todo el orbe.

Al inspeccionar el penthouse de los hermanos se encontraron los restos de la que podía catalogarse como una pelea de amplias dimensiones. Los trofeos, premios, fotografías y recuerdos de tantas personalidades conocidas durante sus años de fama yacían tirados por el suelo, otros sumergidos en la tina, algunos con señales de haber sido quemados.

La noticia de los Pablos, como todo lo que es noticia, se volvió vieja de manera gradual. Los periódicos y noticiarios dejaron diluir la búsqueda a lo largo de los años. Finalmente el lugar de los hermanos pudo suplirse con la pujante imagen de los Ramones. 
Pablo observó el devenir de todo aquel alboroto en una modesta televisión. Con las puertas de la casa abierta, el polvo de su tierra natal que volvía a colarse de manera silenciosa por el techo de lámina vieja. Recostado en una hamaca intentó acomodarse sin mover mucho la cicatriz en su cuello que todavía, después de años, dolía. Echó su ahora única cabeza hacia atrás y decidió olvidarse de todo. 